\title{
UMA ANÁLISE INTERSEMIÓTICA DAS POS- TAGENS DA REVISTA COSMOPOLITAN NO INSTAGRAM
}

\author{
VANESSA HARLOS \\ UNIVERSIDADE FEDERAL DE SANTA MARIA \\ SANTA MARIA, RIO GRANDE DO SUL, BRASIL \\ VANE.HARLLOS@GMAIL.COM \\ CRISTIANE SALETE FLOREK \\ UNIVERSIDADE FEDERAL DE SANTA MARIA \\ SANTA MARIA, RIO GRANDE DO SUL, BRASIL \\ CRISFLOREK@HOTMAIL.COM
}

HTTP://DX.DOI.ORG/10.5902/2316882X26416 


\section{UMA ANÁLISE INTERSEMIÓTICA DAS POSTAGENS DA REVISTA COS- MOPOLITAN NO INSTAGRAM}

Resumo: Neste artigo, apresentamos um estudo sociossemiótico da relação entre linguagem verbal e visual em postagens da Revista Cosmopolitan no Instagram. Os resultados revelam o uso da intertextualidade, da ancoragem entre texto visual e verbal, e de arranjos visuais que representam ação, como algumas das estratégias semióticas empregadas para reafirmar sentidos de senso comum e produzir novos sentidos em torno da vida cotidiana. Palavras-chave: Semiótica; Multimodalidade; Impresso-Digital; Instagram; Cosmopolitan

\section{UN ANÁLISIS INTERSEMIÓTICO DE LAS PUBLICACIONES DE LA RE- VISTA COSMOPOLITAN EN INSTAGRAM}

Resumen: En este artículo, se presenta un estudio de la relación entre los lenguajes verbales y visuales en los puestos de la revista Cosmopolitan en Instagram. Los resultados muestran que el uso de la intertextualidad, el acoplamiento entre el texto visual y verbal, y los arreglos visuales que representan la acción, ya que algunas de las estrategias semióticas empleadas en los textos publicados por Cosmopolitan para reafirmar el sentido común y producir nuevos significados en torno a la vida cotidiana.

Palabras clave: Semiótica; Multimodalidad; Impreso-digital; Instagram; Cosmopolitan.

\section{AN INTESEMIOTIC ANLYSIS OF COSMOPOLITAN MAGAZINE'S POSTS ON INSTAGRAM}

Abstract: This article presents a socio-semiotic study of relationship between verbal and visual languages in Cosmopolitan Magazine's posts on Instagram. Results reveal use of intertextuality, anchoring between visual and verbal text, and visual arrangements that represent action, such as some of the semiotic strategies used to reaffirm common sense and produce new meanings around daily life.

Keywords: Semiotics; Multimodality; Printed-Digital; Instagram; Cosmopolitan. 


\section{INTRODUÇÃO}

As relações econômicas e socioculturais se alteraram sensivelmente ao longo do tempo, criando as condições para a consolidação da atual sociedade da informação, cuja principal moeda de troca são os bens simbólicos em detrimento dos bens materiais. Essas novas relações de produção e de consumo impulsionaram investimentos significativos no campo das tecnologias de informação e de comunicação (p. ex.: rede de computadores, banda larga, telefonia móvel) (BRAGA, 2016). Assim, cada vez mais as plataformas digitais de comunicação vêm sendo aprimoradas, propiciando o aparecimento "dos primeiros portais de notícias, em seguida o surgimento dos blogs, e mais recentemente, das redes sociais e microblogs, como o Facebook e o Twitter" (VIRGINO; BEZERRA; NICOLAU, 2011, p. 3).

Inserido na era da informação e do conhecimento, o jornalismo impresso vive um momento de transformação, uma vez que a web, antes vista como um complemento para os meios de comunicação, passou a ser considerada um recurso indispensável para a imprensa, já que a tecnologia digital permite a distribuição contínua e em tempo real da notícia, multiplicando a capacidade de transmissão de conteúdo e de participação do público, conforme definem Silva, (2012) e Mattos (2013). Ao aderirem aos meios digitais, os meios impressos evitam o risco de perder leitores por não se adequarem às novas tendências, podendo, inclusive, aumentar seu público consumidor por meio do refinamento de suas relações de consumo, estreitadas pelo rápido feedback que as plataformas digitais possibilitam (SANTOS; GOMES; PELLEGRINI, 2015).

A expansão dos serviços de telefonia e de internet móvel estimularam o surgimento de redes sociais exclusivas para aparelhos celulares e tablets. Uma dessas redes é o Instagram "que funciona como uma rede social móvel de fotografias [e, mais recentemente, de vídeos curtos], na qual é possível produzir, editar e compartilhar imagens [e vídeos] de uma só vez" (ARAGÃO, 2012, p. 8). O Instagram oferece uma variedade de "filtros especiais, fazendo com que a imagem tenha, aparentemente, traços artísticos e diferenciados" (OLIVEIRA, 2014, p. 5). Os usuários do Instagram também podem compartilhar suas postagens do microblog em outras redes sociais nas quais possuam uma conta.

Meios de comunicação tradicionalmente impressos, como jornais e revistas, cada vez mais vêm aderindo ao Instagram. Um exemplo a ser

Rev.Cad.Comun. Santa Maria, v.22, n.1, art 8, p.173 de 197, jan/abr.2018 
citado é a Revista Cosmopolitan, que diariamente divulga informações por meio de seu perfil no Instagram. Lançada no Brasil em setembro de 1973, a Revista Cosmopolitan é distribuída pela Editora Abril e traz como conteúdos editorias temas voltados para a mulher, enfatizando questões sobre moda, sexo, beleza, relacionamento, carreira e entretenimento, englobando em seu escopo a proposta de incentivar uma representação forte, poderosa, independente e ousada da mulher (PUBLI ABRIL, 2016). Com 44 anos de existência, a Cosmopolitan, anteriormente chamada de Revista Nova, passou por uma remodelação gráfica e editorial em abril de 2015.

Uma questão central no que concerne às novas mídias e formas de expressão no meio digital diz respeito à linguagem. Assim como no Whatsapp e no Facebook, por exemplo, a linguagem usada no Instagram combina diferentes modos de produção de sentido (verbal, visual, sonoro, p. ex.). Por isso, podemos afirmar que a linguagem usada no Instagram é multimodal, visto que "a multimodalidade no discurso implica o uso de vários modos semióticos" (FONTE; CAIADO, 2014, p. 3).

A era da informação é principalmente marcada pela troca de representações que "resultam da própria interação social, sendo comuns a um grupo social, em determinado tempo e espaço, ou seja, em determinado contexto" (MORAES, et. al, 2013, p. 2-3). Antes de comprarmos um produto, adquirimos o valor simbólico que ele representa no contexto em que nos inserimos e, da mesma forma, estamos constantemente construindo valores simbólicos em torno da nossa existência, o chamado "emitir para existir” (GONÇALVES, et.al, 2016, p. 4). Sob essa ótica, o Instagram possibilita que os indivíduos demonstrem suas representações de mundo ao depositarem parte de sua cultura, seus pensamentos e crenças em um espaço digital, ao mesmo tempo em que consomem representações feitas por outras pessoas, empresas e instituições no mesmo ambiente, evidenciando, desse modo, as relações de consumo subjacentes a essa plataforma digital e que asseguram a sua existência e continuidade.

O Instagram trabalha principalmente com imagens, algo característico das mídias digitais (VIEIRA, 2015). A força de atração e de síntese das imagens (KRESS; VAN LEEUWEN, 2006) fazem dessa rede social um espaço propício para a construção de identidades e para a captação do público (SANTOS; GOMES; PELLEGRINI, 2015). A relação entre os indivíduos e a imagem nunca esteve tão em evidência, atribuindo outros sentidos para as dinâmicas da comunicação e também para a disseminação de informa- 
ções e de notícias. As imagens em geral, e a fotografia especialmente, têm poder estético e informacional, elas geram um mundo onde tudo está conectado (VIEIRA, 2015).

O Instagram atingiu a marca de 10 milhões de usuários já em 2011, um ano após sua criação (OLIVEIRA, 2014). Contando com mais de 600 milhões de usuários espalhados pelo mundo, o Instagram, dispõe de uma variada gama de recursos e funcionalidades, como a postagem de fotos e vídeos (OLIVEIRA, 2014), adição de filtros e, mais recentemente, transmissão de vídeos ao vivo e Instagram Stories' ${ }^{1}$. Além disso, essa rede social possibilita o uso de hashtags ${ }^{2}$ e de legendas nas postagens de fotos e vídeos.

Conforme Salazar (2014, p. 8), as hashtags funcionam como uma espécie de conector entre uma publicação e outra, "formando bancos de dados mutáveis e pouco estáticos". Por funcionarem como legendas, esses recursos são considerados textos verbais que, unidos aos textos visuais, produzem textos multimodais.

$\mathrm{Na}$ pesquisa que relatamos neste artigo, investigamos processos de construção de sentido em textos multimodais oriundos das postagens da Revista Cosmopolitan em seu perfil no Instagram. Com base em uma perspectiva sociossemiótica de linguagem (HALLIDAY, 1978; HODGE; KRESS, 1988; KRESS; VAN LEEUWEN, 1996; 2006; VAN LEEUWEN, 2005), averiguamos a linguagem de tais postagem em termos: i) funcionais: atos de fala materializados pela linguagem; ii) semânticos: quanto aos sentidos que produz; iii) contextuais: averiguando como os sentidos são influenciados pelas situações sociais e culturais em que são produzidos; e iv) semióticos: investigando os recursos linguísticos potencialmente significativos empregados no processo de produção de sentido.

Contamos com um corpus de pesquisa que engloba imagens divulgadas na conta mantida pela Revista Cosmopolitan em seu perfil no Instagram. As imagens foram coletadas tomando como base sua popularidade, medida por meio de curtidas. Essa investigação procura elucidar, ainda que parcialmente, como o texto verbal e o texto visual encontrados nas

1 Também conhecida como "história do Instagram", permite a postagem de fotos e vídeos curtos que desaparecem depois de passadas $24 \mathrm{~h}$ de sua publicação.

2 Comando com função de agrupar imagens relacionadas a um determinado assunto, facilitando a disseminação e organizando o acompanhamento de um conteúdo. As hashtags aparecem sempre acompanhadas do símbolo bemol "\#”. (FERREIRA; PADILHA, 2014).

Rev.Cad.Comun. Santa Maria, v.22, n.1, art 8, p.175 de 197, jan/abr.2018 
postagens feitas pela Cosmopolitan em sua conta no Instagram se inter-relacionam semioticamente e como essa inter-relação produz sentido.

A seguir, apresentamos alguns estudos prévios importantes para 0 desenvolvimento desta pesquisa em virtude de aportarem informações sobre a gramática dos recursos visuais (estáticos) e sobre como tais recursos se concatenam aos verbais (escritos) e, assim, produzem sentido em textos multimodais.

\section{A PRODUÇÃO DE SENTIDO NA ERA DIGITAL}

Segundo Fonte e Caiado (2014, p. 2), "os desafios impostos pela cultura digital envolvem práticas diferenciadas de leitura e de escrita". Todo e qualquer sistema que apresente recursos sistemáticos para a produção de sentido pode ser considerado um modo semiótico. Assim, podemos falar em modo semiótico verbal, que possibilita produzir textos orais e escritos, modo semiótico visual, que possibilita a produção de imagens estáticas e em movimento, modo semiótico musical, entre outros.

A comunicação pela congregação de diferentes modos semióticos não é uma novidade, pois a linguagem é inerentemente multimodal (KRESS; VAN LEEUWEN, 2006). O que vem ocorrendo, atualmente, é a valorização de outros recursos que não somente o verbal escrito no processo de produção e de leitura de textos.

Barthes (1964, p. 38) faz um questionamento sobre a relação que texto e imagem constroem: "Será que a imagem é simplesmente uma duplicata de certas informações que um texto contém e, portanto, um fenômeno de redundância, ou será que o texto acrescenta novas informações à imagem? ". A reflexão de Barthes é bastante pertinente, pois questiona a relação entre texto verbal e texto visual, sua composição, bem como sua disposição espacial nos meios em que estão inseridos. Tudo isso reflete na mensagem que é repassada e também na forma como isso acontece.

\subsection{ANCORAGEM E RELAIS: A RELAÇÃO VERBO-VISUAL}

Especialmente no que concerne ao estudo da inter-relação entre linguagem verbal e linguagem visual, Barthes $(1977,1990)$ pode ser considerado um precursor pelas investigações que desenvolveu com fotografias e anúncios publicitários e das quais decorrem sua teoria de que, em um texto, visual e verbal podem estabelecer uma relação de dependência (an-

Rev.Cad.Comun. Santa Maria, v.22, n.1, art 8, p.176 de 197, jan/abr.2018 
coragem) ou de complementaridade (relais). No caso da ancoragem, também chamada de fixação, a linguagem verbal delimitaria o sentido polissêmico da linguagem visual (BARTHES, 1990) de modo que o texto verbal serviria como uma espécie de base, uma legenda, que guia o leitor para que este possa realizar a leitura do texto visual, pois "direciona o leitor para o significado da imagem, ajudando-o a identificar os elementos dela" (FONTE; CAIADO, 2014, p. 478). No caso do relais, termo em francês que pode ser traduzido como alternância, a linguagem verbal e a linguagem visual seriam fragmentos de uma unidade semântica superior resultante da complementaridade semântica entre esses dois modos de produção de sentido (BARTHES, 1990).

Em termos de análise sistemática, a Gramática do Design Visual (KRESS; VAN LEEUWEN, 2006) é um aparato teórico-metodológico que permite analisar imagens como se fossem textos verbais, isto é, possuidores de uma gramática e de relações de coesão e de coerência. A Gramática do Design Visual, inspirada nos estudos de Halliday e Matthiessen (1994; 2004) sobre a linguagem verbal pela perspectiva da Linguística Sistêmico-Funcional, descreve e sistematiza as bases linguísticas dos hábitos visuais consensualmente estabelecidos nas sociedades ocidentais.

\subsection{GRAMÁTICA DO DESIGN VISUAL}

A Gramática do Design Visual (KRESS; VAN LEEUWEN, 2006) é importante nesta pesquisa, pois, conforme esse construto teórico-metodológico, o texto visual e o texto verbal possuem semelhanças entre si, visto que as imagens teriam o equivalente a um léxico e uma gramática na linguagem verbal. Segundo Hendges, Nascimento e Marques (2013, p. 242), "enquanto que na linguagem verbal o léxico se realiza por meio de palavras, nas imagens, ele equivale aos diferentes volumes e formas que podemos distinguir na imagem" e que se materializam "no modo como esses volumes e formas retratados se combinam em orações visuais de maior ou menor complexidade e extensão".

Segundo Kress e Van Leeuwen (2006), as escolhas realizadas pelos usuários do modo semiótico visual nas mais diversas situações comunicativas resultam em redes de significados que, simultaneamente, têm relação com: i) o conteúdo e as experiências que o falante pretende representar (metafunção representacional); ii) com as relações interpessoais que se

Rev.Cad.Comun. Santa Maria, v.22, n.1, art 8, p.177 de 197, jan/abr.2018 
estabelecem entre os participantes representados e os participantes interativos - produtor e consumidor da imagem - (metafunção interativa); e iii) com o modo como o texto é construído como uma unidade semântica ordenada e significativa (metafunção composicional).

Na presente pesquisa, enfatizamos a investigação dos processos de materialização da metafunção representacional nas amostras que compõem nosso corpus. Como a própria nomenclatura indica, a metafunção representacional desempenha o papel de representar a realidade sensível, em virtude do potencial que "as imagens em geral têm para representar visualmente a experiência humana (KRESS; VAN LEEUWEN, 2006). A metafunção representacional é realizada por: i) estruturas de ação (estruturas narrativas); ou ii) estruturas que classificam, revelam a composição ou conferem significado aos participantes representados (estruturas conceituais). Conforme Kress e Van Leeuwen (2006), a representação da realidade acontece por meio de três elementos distintos pertencentes a essas estruturas: participantes, processos e circunstâncias.

Os participantes dividem-se em dois tipos: interativos e representados. Os interativos são os atores envolvidos no ato comunicacional, os produtores e leitores da imagem. Já os participantes representados são o assunto desse ato (pessoas, coisas, lugares). Os processos podem ser de dois tipos: narrativos ou conceituais. Nos processos narrativos, existe a presença de um vetor, ou seja, "linhas diagonais formadas por braços, pernas, ou a linha do olhar" (HENDGES; NASCIMENTO; MARQUES, 2013, p. 245), que atua como conector entre os participantes representados e suas ações uns para com os outros. Os tipos de vetores são variados, assim como os tipos de processos narrativos, que são seis: a) ação, b) reação, c) verbais, d) mentais, e) de conversão e f) simbolismo geométrico (Quadro 1). 


\begin{tabular}{|c|c|c|c|}
\hline Tipos & Participantes & Conceitos & Exemplos \\
\hline $\begin{array}{l}\text { Açào: } \\
\text { Transicional }\end{array}$ & Ator-meta & Ator realiza uma açào em direção a uma meta. & \\
\hline $\begin{array}{l}\text { Não- } \\
\text { transicional }\end{array}$ & Ator & $\begin{array}{l}\text { Ação do ator não é direcionada para } \\
\text { algo/alguém. }\end{array}$ & \\
\hline $\begin{array}{l}\text { Reaç̃o: } \\
\text { Transicional }\end{array}$ & $\begin{array}{l}\text { Reator- } \\
\text { fenômeno }\end{array}$ & $\begin{array}{l}\text { Reator é quem olha e o fenômeno é o foco do } \\
\text { olhar. }\end{array}$ & \\
\hline $\begin{array}{l}\text { Não- } \\
\text { transicional }\end{array}$ & Reator & $\begin{array}{l}\text { Olhar do ator em direção ao participante } \\
\text { interativo, que é quem está vendo a imagem, } \\
\text { provocando empatia. }\end{array}$ & \\
\hline Verbais & Dizente & $\begin{array}{l}\text { Possuem um dizente, que é um vetor que } \\
\text { conecta os participantes aos conteúdos por } \\
\text { meio de um balão de diálogo. }\end{array}$ & \\
\hline Mentais & Experenciador & $\begin{array}{l}\text { Participantes representados são conectados aos } \\
\text { conteúdos por meio de um balão de } \\
\text { pensamento, chamado de vetor experenciador. }\end{array}$ & \\
\hline Conversão & Ator-meta & $\begin{array}{l}\text { Meta de um processo se torna o autor de outro, } \\
\text { realizando uma ação ao próximo participante. }\end{array}$ & \\
\hline $\begin{array}{l}\text { Simbolismo } \\
\text { geométrico }\end{array}$ & $\begin{array}{l}\text { Sem } \\
\text { participantes }\end{array}$ & $\begin{array}{l}\text { Acontece por meio de flechas e setas que } \\
\text { exploram o valor simbólico dos elementos. }\end{array}$ & \\
\hline
\end{tabular}

Quadro 1- Exemplos processos narrativos

Fonte: Elaborado pelas autoras

As circunstâncias envolvem participantes considerados secundários na realização das ações, mas que, conforme Kress e Van Leeuwen (2006), mantêm relação com os participantes primários por meio de três formas: circunstância de lugar (cenário onde acontece a ação), de meio (ferramentas usadas para realizar a ação) e de acompanhamento (apresentação dos participantes).

Além dos processos narrativos, existem os processos conceituais. Segundo Hendges, Nascimento e Marques (2013, p. 246), esses processos "enfatizam o que os participantes são, não as atividades que realizam. Neles, pessoas, objetos e seres são captados por alguns de seus atributos e pelo conceito que representam". Existem três tipos de processos conceituais: classificacionais, analíticos e simbólicos (Quadro 2). 


\begin{tabular}{|c|c|c|c|}
\hline Tipo & Participantes & Conceito & Exemplos \\
\hline Classificacionais & $\begin{array}{c}\text { Superordenado } \\
\text { Subordinado }\end{array}$ & $\begin{array}{l}\text { Participantes são representados de } \\
\text { maneira simétrica, de forma a focar } \\
\text { em suas caracteristicas enquanto } \\
\text { integrantes de um grupo/categoria. } \\
\text { A classificação pode ser implicita } \\
\text { ou explicita }\end{array}$ & \\
\hline Analíticos & $\begin{array}{l}\text { Portador } \\
\text { Atributos } \\
\text { Possessivos }\end{array}$ & $\begin{array}{l}\text { Os participantes são representados } \\
\text { na sequência parte-todo, em que os } \\
\text { atributos pessoais representam as } \\
\text { partes e o portador representa o } \\
\text { todo. }\end{array}$ & \\
\hline Simbólicos & $\begin{array}{l}\text { Portador } \\
\text { Atributos } \\
\text { Portador }\end{array}$ & $\begin{array}{l}\text { Referem-se ao significado } \\
\text { atribuido a determinado } \\
\text { participante representado. Para } \\
\text { tanto, os processos simbólicos } \\
\text { podem ser atributivos ou } \\
\text { sugestivos. São atributivos quando } \\
\text { o portador possui atributos de outro } \\
\text { participante representado, e } \\
\text { sugestivos quando o portador já } \\
\text { tem um significado, tido como um } \\
\text { signo. }\end{array}$ & mensistist \\
\hline
\end{tabular}

Quadro 2- Exemplos processos conceituais

Fonte: Elaborado pelas autoras

Os efeitos de sentido produzidos em um texto, normalmente, têm origem na fusão de uma informação nova com conhecimentos trazidos de outros textos, ao que autores como Kristeva (2005) e Koch, Bentes e Cavalcante (2008), com base nos estudos e descobertas de Bakhtin (1997), denominaram intertextualidade.

\subsection{A INTERTEXTUALIDADE: OS TEXTOS POR DETRÁS DO TEXTO}

Neste trabalho, ao tratarmos sobre a relação entre texto verbal escrito e texto visual estático foi praticamente impossível ignorar as questões ligadas à intertextualidade, uma vez que elas são notáveis nos posts da Cosmopolitan no Instagram. O filósofo russo Mikhail Bakthin foi quem inicialmente trabalhou com o conceito da intertextualidade, tratando-a como dialogismo (FREITAS, 2011). O dialogismo bakhtiano é definido como as diferentes vozes que estão presentes em um enunciado e que se mani- 
festam por meio da interação textual, uma vez que leitor e o produtor do texto são agentes sócio historicamente situados que compartilham um espaço de interação.

O termo intertextualidade apareceu de fato na década de 60 , a partir dos estudos da semioticista Julia Kristeva, que teve por base o conceito bakhtiniano de dialogismo. Conforme Kristeva (2005, p. 68), "todo texto se constrói como mosaico de citações, todo texto é absorção e transformação de um outro texto". A visão da autora trata ainda da questão do intertexto produzido pelo leitor, peça chave para que a intertextualidade aconteça.

Para que ocorra a intertextualidade, é necessário que o leitor possa reconhecer a presença de outro texto ou de fragmentos produzidos anteriormente, que estabeleçam relação com o texto lido. Em outros termos, é preciso que haja a presença de um "intertexto" (FREITAS, 2011, p. 31).

Unindo-se aos pesquisadores interessados na intertextualidade, figuram Koch que, em 2008, juntamente com Bentes e Cavalcante, aprofundam e criam novos vieses para o termo, propondo separá-lo em "dois grandes blocos: intertextualidade stricto sensu e intertextualidade lato sensu" (FREITAS, 2011, p. 32). Na intertextualidade lato sensu, a materialização do intertexto não é obrigatória, uma vez que ela é "constitutiva de todo e qualquer discurso" (MATOS, 2008, p. 4), ou seja, aparece em "sentido amplo" (SANTOS, 2013, p. 301).

Já no bloco stricto sensu, inserido em um texto está outro, o chamado intertexto, previamente produzido e que "faz parte da memória social de uma coletividade ou da memória discursiva (...) dos interlocutores" (KOCH; BENTS; CAVALCANTE, 2008, p. 17). Aqui, o diálogo entre os textos é estabelecido com a "materialização do intertexto" (SANTOS, 2013 p. 301). Dentro da intertextualidade stricto sensu, existem quatro categorias: temática, estilística, implícita e explícita.

A intertextualidade temática é encontrada entre textos pertencentes a uma mesma área do saber ou mesma corrente de pensamento, que partilham temas e se servem de conceitos e terminologia próprios. A estilística ocorre nas repetições, imitações e paródia de alguns estilos ou variedades linguísticas. Na intertextualidade explícita é feita, no próprio texto, menção à fonte do intertexto, como ocorre, por exemplo, nas citações,

Rev.Cad.Comun. Santa Maria, v.22, n.1, art 8, p.181 de 197, jan/abr.2018 
referências, menções, resumos, resenhas e traduções. Já na intertextualidade implícita não há qualquer menção à fonte do intertexto alheio, ainda que o produtor do texto espere que seu interlocutor reconheça a presença do intertexto pela ativação do texto-fonte em sua memória discursiva (MATOS, 2008, p. 5).

Essa categorização da intertextualidade sinaliza o quanto a intertextualidade é fundamental nos textos verbais e, também, de outras naturezas, mesmo que, por vezes, ocorra de forma subentendida, "em que o locutor apresenta seus atos de linguagem como um enigma a ser decifrado" (KOCH, 2008, p. 25). As imagens coletadas do Instagram da Cosmopolitan não fogem à regra e se encaixam nesse enigma.

\section{PROCEDIMENTOS METOdOLÓGICOS}

Antes de iniciarmos a explicação dos processos envolvendo a metodologia desta pesquisa, recordamos a pergunta que norteia este trabalho: como acontece a relação entre o texto verbal e o texto visual encontrados nas postagens feitas pela Cosmopolitan em sua conta no Instagram e como essa inter-relação semiótica produz sentido? No intuito de respondê-la, passamos, nas próximas seções, à apresentação de nosso corpus, dos procedimentos e categorias que empregamos em nossa análise e, finalmente, dos resultados que encontramos.

\subsection{O UNIVERSO DE ANÁLISE}

Segundo dados extraídos do site oficial da Editora Abril (2016), a revista Cosmopolitan abrange um público de $86 \%$ de mulheres e $14 \%$ de homens, totalizando a marca de 686 mil leitores. A tiragem média líquida de exemplares da revista gira em torno de 69.213 mil cópias. Desse total, $58.811 \mathrm{mil}$ são assinaturas e 9.402 mil são exemplares comprados de forma avulsa. A revista conta ainda com perfis nas redes sociais Facebook, Twitter, Snapchat e Instagram.

Quanto ao conteúdo divulgado em seu Instagram, conforme detaIharemos em nossa análise, a Cosmopolitan publica textos que abordam questões universais da existência humana por meio de representações visuais e verbais de temas da vida cotidiana, como alimentação, cansaço/ sono, motivação e comportamento, com destaque para imagens retiradas de filmes ou de obras culturais conhecidas. Algumas dessas postagens

Rev.Cad.Comun. Santa Maria, v.22, n.1, art 8, p.182 de 197, jan/abr.2018 
combinam texto verbal escrito e texto visual estático, outras apresentam predominantemente texto visual estático e outras ainda apresentam predomínio do texto verbal escrito.

\subsection{O CORPUS}

O corpus desta pesquisa é constituído por 12 posts publicados no perfil da Cosmopolitan no Instagram entre março de 2015 e fevereiro de 2016. O critério de seleção usado foi o da imagem mais curtida em cada mês. Para isso, observando a data de postagem e também quantas curtidas cada foto possuía, fizemos um print ${ }^{3}$ na foto mais curtida, uma vez que o Instagram não oferece a opção de copiar ou mesmo salvar as imagens. A seguir, apresentamos uma tabela com as imagens capturadas, já codificadas ${ }^{4}$ e também com o número de curtidas que cada foto recebeu. As imagens desse corpus podem ser consultadas em tamanho maior no Anexo A deste artigo.

3 Tecla de computador que "fotografa" tudo que estiver na tela no momento em que é pressionada.

4 Para fins de organização, cada imagem recebeu um código de identificação, composto pela letra "C", de Cosmopolitan, as três primeiras letras do mês no qual foi postada, o ano da postagem, um sinal de \#, a ser lido como número, seguido do número que corresponde a ordem de coleta (1,2, 3.. até o 12, pois são doze fotos).

Rev.Cad.Comun. Santa Maria, v.22, n.1, art 8, p.183 de 197, jan/abr.2018 


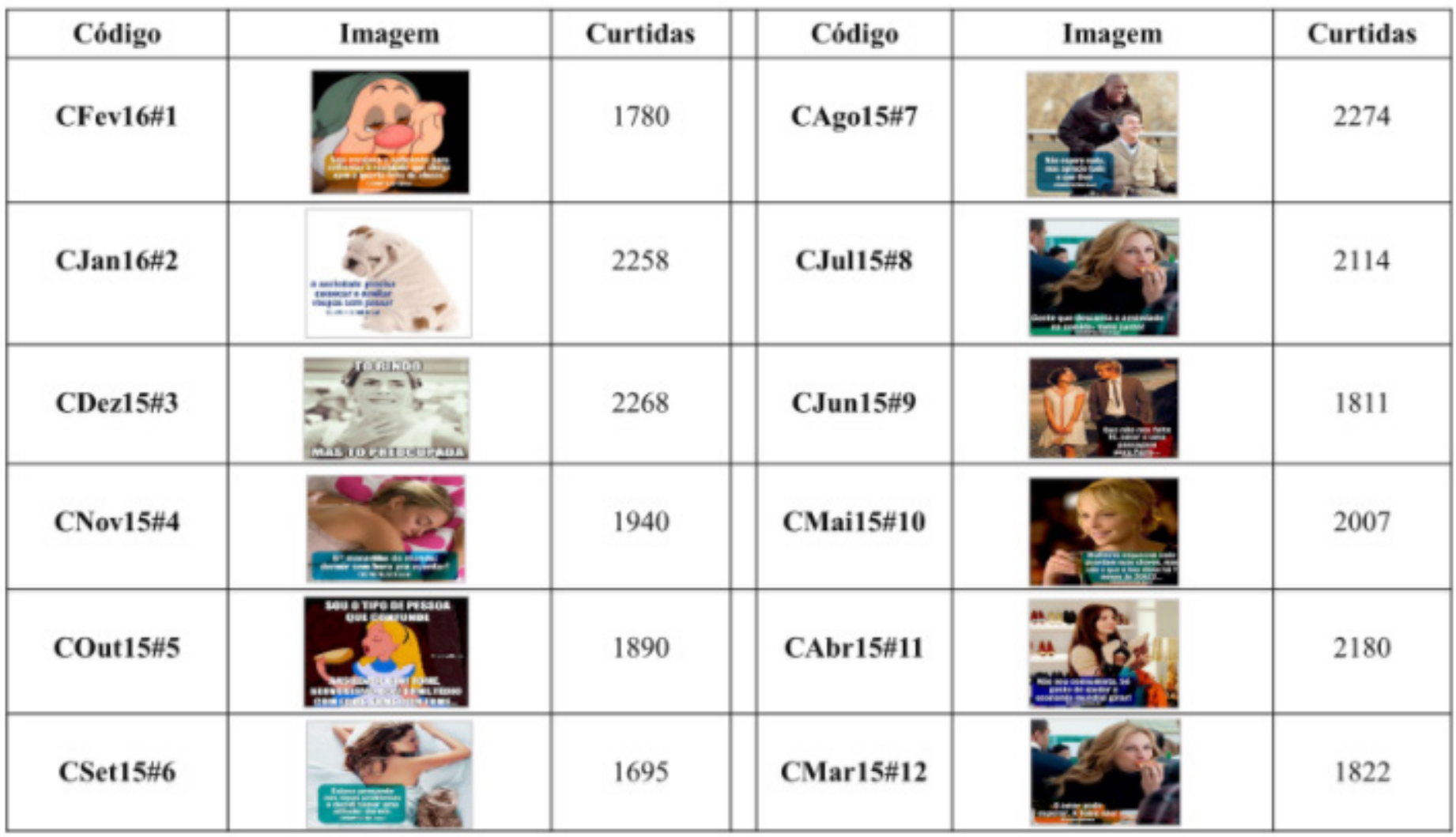

Quadro 3- Imagens coletadas do Instagram da Cosmopolitan

Fonte: Elaborado pelas autoras

\subsection{PROCEDIMENTOS E CATEGORIAS DE ANÁLISE}

Tendo coletado o corpus deste trabalho, passamos à etapa de análise. Primeiramente, analisamos as imagens coletadas à luz da metafunção representacional (KRESS; VAN LEEUWEN, 2006). Também agrupamos as imagens em categorias temáticas, uma vez que observamos um padrão de temas recorrentes presentes nas imagens.

Em seguida, fizemos uma análise da relação existente entre o texto verbal escrito e o visual estático, lançando mão das categorias de ancoragem (fixação) e relais (alternância), propostas por Barthes (1990). Para finalizar, ainda quanto à relação linguagem verbal-visual, observamos a presença da intertextualidade (KOCH, BENTES, CAVALCANTE, 2008) e o seu papel para a construção do sentido.

\section{RESULTADOS E DISCUSSÃo}

A fim de facilitar a descrição, agrupamos os resultados obtidos a partir da investigação das imagens em um quadro (Quadro 4). Esse quadro traz, 
primeiramente, os códigos das imagens e, posteriormente, os resultados segundo a ordem dos procedimentos de análise: metafunção representacional, relação entre linguagem verbal e linguagem visual e intertextualidade.

Como já foi mencionado, os textos escolhidos são compostos por um texto visual que vem acompanhado de um breve texto verbal. O texto visual foi o primeiro a ser analisado, em termos daquilo que representa, ou seja, de como a metafunção representacional (KRESS; VAN LEEUWEN, 2006) se realiza.

Das 12 imagens selecionadas, seis (50\%) apresentam processos narrativos de ação transacional (COut15\#5, CAg015\#7, CJul15\#8, CJun15\#9, CAbr15\#11 e CMar15\#12). Tomamos como exemplo a imagem COut15\#5, nela, a personagem Alice, do filme "Alice no País das Maravilhas" configura-se como o ator que possui o pão como meta. O braço da personagem forma um vetor em direção à meta, caracterizando, por isso, um processo narrativo transacional. Nessas imagens, os participantes estão desempenhando ações que "constroem a experiência como um evento que se desencadeia no espaço e no tempo" (FONTE; CAIADO, 2014, p. 534), e que, por isso, trazem um esboço da realidade na percepção do produtor da imagem. 


\begin{tabular}{|c|c|c|c|}
\hline Imagens & Metafunção representacional & Relação texto-imagem & Intertextualidade \\
\hline CFev16\#1 & $\begin{array}{l}\text { Processo conceitual simbólico } \\
\text { sugestivo- o anão, Soneca do } \\
\text { filme "A Branca de Neve", já } \\
\text { possui um significado pré- } \\
\text { definido. }\end{array}$ & $\begin{array}{l}\text { Relais - a mensagem só } \\
\text { compreendida quando o leitor } \\
\text { observa texto e imagem, pois é } \\
\text { preciso olhar para ambos para } \\
\text { compreender a mensagem. O } \\
\text { sintagma maior aqui é o sono. }\end{array}$ & $\begin{array}{l}\text { Stricto sensu implicita- há o uso de uma } \\
\text { imagem do Soneca, personagem do } \\
\text { filme "Branca de Neve e os Sete } \\
\text { Anões" no texto e, ao passo que ela não } \\
\text { é referenciada, pressupõe-se que o leitor } \\
\text { irá entender o que está subentendido. }\end{array}$ \\
\hline CDez15\#3 & $\begin{array}{l}\text { Processo narrativo de reação não- } \\
\text { transicional- o olhar da atriz } \\
\text { Maitê Proença está direcionado } \\
\text { para algo/alguém que não é } \\
\text { possivel identificar. }\end{array}$ & $\begin{array}{l}\text { Ancoragem - o texto "tô rindo' } \\
\text { remete o leitor a imagem da atriz } \\
\text { Maitê Proença sorrindo, } \\
\text { funcionando como uma legenda. }\end{array}$ & $\begin{array}{l}\text { Stricto sensu implicita- apresenta a atriz } \\
\text { Maitê Proença, mas não identificamos o } \\
\text { contexto ao qual ela se encontra (cena } \\
\text { de novela, de filme..). }\end{array}$ \\
\hline COut15\#5 & $\begin{array}{l}\text { Processo narrativo de ação } \\
\text { transicional- Ator: Alice, } \\
\text { personagem do filme "Alice no } \\
\text { País das Maravilhas". Meta: pão } \\
\text { Vetor: mão da Alice. }\end{array}$ & $\begin{array}{l}\text { Ancoragem - o texto trata da questão } \\
\text { da fome e direciona o leitor para a } \\
\text { imagem da Alice comendo um } \\
\text { pedaço de pão. }\end{array}$ & $\begin{array}{l}\text { Stricto sensu implicita- traz a } \\
\text { personagem Alice, do filme "Alice no } \\
\text { País das Maravilhas" comendo um } \\
\text { pedaço de pão para ilustrar o texto } \\
\text { referente à fome. }\end{array}$ \\
\hline CSet15\#6 & $\begin{array}{l}\text { Processo narrativo de ação não- } \\
\text { transicional- ação não é realizada } \\
\text { em direção a alguém. }\end{array}$ & $\begin{array}{l}\text { Ancoragem - assim como na } \\
\text { imagem CNov15\#4, o texto } \\
\text { novamente direciona o leitor para a } \\
\text { imagem de uma moça dormindo. }\end{array}$ & $\begin{array}{l}\text { Stricto Sensu temática- tanto o texto } \\
\text { verbal quanto o visual trabalham com a } \\
\text { temática sono, traduzida no ato de } \\
\text { dormir. }\end{array}$ \\
\hline CJul15\#8 & $\begin{array}{l}\text { Processo narrativo de ação } \\
\text { transicional- Ator: Julia Roberts } \\
\text { (cena do filme "Comer, Rezar, } \\
\text { Amar". Vetor: mão da atriz. Meta: } \\
\text { pizza. }\end{array}$ & $\begin{array}{l}\text { Ancoragem - ao ler o texto, o leitor é } \\
\text { direcionado de imediato para o } \\
\text { pedaço de pizza que a atriz Julia } \\
\text { Roberts está comendo. }\end{array}$ & $\begin{array}{l}\text { Stricto sensu implícita- traz a atriz Julia } \\
\text { Roberts em uma cena do filme "Comer, } \\
\text { Rezar e Amar", fazendo uma analogia } \\
\text { com a palavra "comer", presente no } \\
\text { texto verbal. }\end{array}$ \\
\hline CJun15\#9 & $\begin{array}{l}\text { Processo narrativo de ação } \\
\text { transicional- } 4 \text { ambos } r \text { os } \\
\text { personagens do filme "Meia } \\
\text { Noite em Paris" estão olhando um } \\
\text { para o outro, constituindo-se } \\
\text { como ator e } \\
\text { simultaneamente. }\end{array}$ & $\begin{array}{l}\text { Ancoragem - o texto verbal cria uma } \\
\text { legenda, uma espécie de caminho de } \\
\text { leitura da imagem que poderia trazer } \\
\text { sentidos variados. }\end{array}$ & $\begin{array}{l}\text { Stricto sensu implicita- traz a palavra } \\
\text { "Paris" no texto que remete para uma } \\
\text { cena do filme "Meia Noite em Paris", } \\
\text { usada para ilustrar o texto. }\end{array}$ \\
\hline CMai15\#10 & $\begin{array}{l}\text { Processo narrativo de reação não- } \\
\text { transicional- olhar da moça } \\
\text { direcionado para algo/alguém que } \\
\text { não é possivel identificar. }\end{array}$ & $\begin{array}{l}\text { Relais - sintagma maior é a mulher. } \\
\text { É preciso fazer a leitura do texto e } \\
\text { da imagem para entender a } \\
\text { mensagem. }\end{array}$ & $\begin{array}{l}\text { Stricto sensu implicita- apresenta uma } \\
\text { atriz famosa, mas não identificamos } \\
\text { quem é a triz e a qual filme a cena da } \\
\text { imagem se refere e se é de algum filme. }\end{array}$ \\
\hline CAbr15\#11 & $\begin{array}{l}\text { Processo narrativo de ação } \\
\text { transicional- Ator: Andra ( Anne } \\
\text { Hathway, "O Diabor Veste } \\
\text { Prada"). Meta: sapatos. Vetor: } \\
\text { mãos. }\end{array}$ & $\begin{array}{l}\text { Ancoragem - o leitor pode } \\
\text { identificar o consumismo do qual } \\
\text { fala o texto ao olhar para os vários } \\
\text { sapatos que a atriz Anne Hathway, } \\
\text { em uma cena do Filme " Diabo } \\
\text { Veste Prada', segura. }\end{array}$ & $\begin{array}{l}\text { Stricto sensu implicita- traz referências } \\
\text { do filme "O Diabo Veste Prada", ao } \\
\text { usar uma imagem da personagem } \\
\text { Andra, interpretada pela atriz Anne } \\
\text { Hathway, para ancorar o texto. }\end{array}$ \\
\hline
\end{tabular}


Especificamente nas imagens que apresentam processos narrativos transacionais, as mensagens compreendem questões pontuais da vida cotidiana, como alimentação, cansaço, desejo e comportamento, estado de espírito, externadas no texto visual por meio da imagem de atrizes, atores e personagens famosos. Uma vez que a Cosmopolitan é uma revista voltada principalmente para o público feminino, isso demonstra que ela usa seu perfil no Instagram para provocar uma aproximação maior com seu público, pois, por exemplo, ao trazer uma foto com a atriz Julia Roberts (CJul15\#8 e CMar15\#12) comendo um pedaço de pizza em uma cena do filme "Comer, Rezar, Amar", desnaturaliza uma série de sensos comuns em torno da vida das celebridades e demonstra que a fome é algo comum para qualquer tipo de mulher, até mesmo para as atrizes. Dessa forma, a revista consegue criar um elo com seu público, atingindo mulheres "reais" (donas de casa, profissionais de outros segmentos) com as quais busca estabelecer uma relação empática e de identificação com ícones conhecidos no mundo cultural.

De acordo com nossos resultados, duas imagens (16,6\%) (CFev16\#1 e CJan16\#2) apresentam processos conceituais simbólicos sugestivos. $\mathrm{Na}$ foto do mês de janeiro, o texto visual traz um cachorro da raça Shar-pei consorciado ao texto verbal: "A sociedade precisa começar a aceitar roupas sem passar”. Como característica da raça, o cachorro possui dobras em sua pele. Consensualmente, essa característica física da raça remete a representações como fofura e delicadeza, que são acionadas pelo público da Cosmopolitan no ato da leitura do texto. Na fotografia do mês de fevereiro, o texto visual é composto de um anão, o personagem Soneca do filme "A Branca de Neve e os Sete Anões", que vem acompanhado do texto verbal: "Seja corajosa o suficiente para enfrentar a realidade que chega com a quarta-feira de cinzas". O anão está com uma expressão de sono e demonstra cansaço. Esses indícios, juntamente com o texto verbal, fazem com que os leitores da Cosmopolitan se identifiquem com o estado de espírito "pós-carnaval", pois, depois de noites de festa, o sono e o cansaço são naturais.

A leitura de textos visuais que apresentam processos simbólicos sugestivos, demanda, de maneira especial, o acionamento de conhecimentos prévios do leitor. Tais conhecimentos precisam ser identificados e decodificados para que o processo de recepção das mensagens e de produção de sentido ocorra conforme pretendido pelo produtor da imagem. Essas

Rev.Cad.Comun. Santa Maria, v.22, n.1, art 8, p.187 de 197, jan/abr.2018 
duas imagens trabalham com questões bastante conhecidas pelo público em geral: as características dos cães de raça Shar-pei, ao que se associam, a uma série de valores ideológicos gerais (cão de companhia, relativamente caro, de raça) e as características do personagem Soneca, que remetem a valores como o "preguiçoso do bem", desnaturalizando a noção do sono/ preguiça como algo negativo. Assim, de uma forma muito sutil, sem demandar conhecimentos altamente elaborados, pelo contrário, decorrentes da experiência em nossa sociedade, a Revista Cosmopolitan produz sentidos em torno de questões cotidianas vivenciadas pelas pessoas em geral.

Temas como sono, fome e relacionamentos estão presentes também nos textos verbais que acompanham os textos visuais que acabamos de analisar. Neste trabalho, os textos verbais fazem parte da segunda etapa da nossa análise, realizada a partir das categorias de ancoragem e relais (BARTHES, 1990). A relação entre o texto verbal e texto visual se dá por meio do recurso de ancoragem em nove (75\%) das doze imagens analisadas (CJan16\#2, CDez15\#3, CNov15\#4, COut15\#5, CSet156, CJul15\#8, CJun15\#9, CAbr15\#11 e CMar15\#12). Como exemplo temos a imagem CJul15\#8, cujo texto verbal diz "Gente que desconta a ansiedade na comida: tamo junto" e traz o texto visual de uma cena do filme "Comer, Rezar, Amar", em que a atriz Julia Roberts está comendo um pedaço de pizza. Ao ler o texto verbal, o leitor é direcionado para o pedaço de pizza e o ato de comer ilustrado na imagem, pois a ancoragem desempenha o papel de legenda do texto visual, "guiando o leitor" (FONTE; CAIADO, 2014, p.478) para o significado da imagem, ou seja, para sua mensagem, "logo, o texto serve de base para a leitura da imagem" (FONTE; CAIADO, 2014, p.478). O nível mais coloquial expresso pela linguagem verbal ("tamo junto"), e que é recorrente em outros textos analisados, reforça o empenho do produtor do texto em criar uma relação de identificação com o seu leitor por meio de questões da vida diária.

Em três (25\%) das 12 imagens analisadas, a relação entre texto visual e verbal ocorre por meio de relais, o que significa que tais imagens demandam uma leitura particularizada da mensagem visual e da mensagem verbal para atingir um sentido maior, que se constrói na complementaridade do visual e do verbal. Como exemplo, temos o texto verbal "Mulheres esquecem onde guardam suas chaves, mas não o que o boy disse há 7 meses, às 20h22..." (CMai15\#10). Junto dele, a imagem de uma mulher compõe o texto visual. Para que a mensagem seja compreendida, o leitor precisará observar ambos os textos, pois ao olhar apenas para a mulher será levado a crer que ela saiu

Rev.Cad.Comun. Santa Maria, v.22, n.1, art 8, p.188 de 197, jan/abr.2018 
para uma festa ou jantar, no entanto, ela ilustra uma situação geral: a boa memória feminina nas questões sentimentais e de lembrança afetiva, fato que está presente nas linhas do texto verbal. Nas três fotos, a relação imagem-texto é semelhante, uma vez que os sentidos da mensagem estão distribuídos ao longo do texto verbal e do texto visual. Por isso a necessidade de se observar ambos os textos.

Como nossos resultados já vem apontando, no ciclo emissor-mensagem-receptor, a produção efetiva do sentido depende da bagagem cultural e de conhecimentos prévios do leitor, que lhe permitam compreender o conteúdo das postagens da Cosmopolitan, pois "os conhecimentos das formas, das interações e relações sociais podem ser transmitidos pelas imagens, mas o leitor só será o ideal caso compartilhe desses valores ou, então, opte por atualizar seus valores a partir daquela imagem ou situação comunicativa" (SANTOS; MEIA, 2010, p. 308). Essa citação de Santos e Meia (2010) nos remete à última etapa da nossa análise, que traz à tona a questão da intertextualidade (KOCH; BENTES; CAVALCANTE, 2008), encontrada na forma implícita em dez textos (83,3\%) do nosso corpus (CFev16\#1, CJan16\#2, CDez15\#3, COut15\#5, CAg015\#7, CJul15\#8, CJun15\#9, CMai15\#10, CAbri15\#11 e CMar15\#12), de forma explícita em um exemplar de nosso corpus $(8,3 \%)$ (CNov15\#4) e de forma temática em mais um exemplar (8,3\%) (CSet15\#6).

Em CFev16\#1, a intertextualidade se configura como stricto sensu implícita ao se relacionar ao texto verbal "Seja corajosa o suficiente para enfrentar a realidade que chega com a quarta-feira de cinzas", e ao texto visual representado pelo personagem Soneca do filme "A Branca de Neve e os Sete Anões", referindo-se ao fato de voltar para realidade após as comemorações de Carnaval e a quarta-feira de cinzas. Isso mostra que a intertextualidade não se restringe somente ao texto verbal, mas "podemos ter uma intertextualidade entre uma imagem e um texto verbal, por exemplo" (SANTOS, 2013, p. 306).

Em nosso corpus de pesquisa, a teoria proposta por Koch, Bentes e Cavalcante (2008) em torno das categorias da intertextualidade tem uma leitura um pouco diferente. A intertextualidade, inicialmente tida como implícita, passa a ser explícita a partir do momento em que o leitor, ao rememorar outros textos visuais e verbais que tenha lido/visto anteriormente, consegue reconhecer as cenas famosas presentes nos posts, uma vez que, ao que parece, a Cosmopolitan, produtora do conteúdo, almeja que seu público "reconheça a presença do intertexto pela ativação do texto-fonte em

Rev.Cad.Comun. Santa Maria, v.22, n.1, art 8, p.189 de 197, jan/abr.2018 
sua memória discursiva" (MATOS, 2008, p. 5).

No caso das postagens da Cosmopolitan, o corpus de pesquisa foi coletado levando em conta o critério de seleção da imagem mais curtida, o que levanta a possibilidade de que um grande número de leitores possa ter se identificado com esses posts em especial. Isso não significa que eles tenham reconhecido o intertexto ali presente de forma imediata, mas não se descarta a possibilidade de que, ao acionarem suas memórias, tenham identificado outros elementos, como uso da cor, diagramação, luz, etc., que os direcionaram para personagens de filmes famosos, o que, de certa forma, fez com que notassem a presença de intertextualidade.

Foi exatamente esse processo que aconteceu com duas imagens do nosso corpus. Na CDez15\#3, a intertextualidade ocorre na forma stricto senso implícita, em que o texto visual é composto pela atriz Maitê Proença, contudo, não identificamos se ela está em uma cena de algum filme ou novela, ou se o texto verbal "Tô rindo, mas tô preocupada" é um bordão famoso ou algo que se popularizou na internet. No entanto, ao ativarmos nossos conhecimentos prévios e reconhecermos quem está representado na imagem, produzimos sentido. É preciso levar em conta também o ofício do ator/ atriz, que é justamente o de interpretar, por isso o paradoxo entre os textos verbal-visual, em que externamente a atriz está rindo, mas, em seu interior, esboça preocupação. O mesmo ocorreu com a imagem CMai15\#10, em que temos o conhecimento prévio de que a moça presente no texto visual é uma atriz. No entanto, o contexto no qual ela está inserida é, para nós, desconhecido.

Os discursos estão em constante processo de produção e atualização de sentido, pois cada sujeito que se coloca em contato com eles irá interpretá-los de formas relativamente distintas, produzindo novas significações. Essas formas relativamente distintas de produzir sentidos geram uma polissemia discursiva que é "justamente a simultaneidade de movimentos distintos de sentido no mesmo objeto simbólico” (ORLANDI, 2009, p. 38). Logo, cada um dos leitores da Cosmopolitan que entrou em contato com os textos CDez15\#3 e CMai15\#10, e com os demais textos analisados em nossa pesquisa, inclusive nós mesmos, independentemente de ter identificado a presença da intertextualidade de forma completa ou não, produziu novos sentidos em cima de sentidos já existentes. 


\section{CONSIDERAÇÕES FINAIS}

Ao analisarmos de forma mais aprofundada as imagens publicadas pela Cosmopolitan em seu Instagram foi possível identificar como acontece a relação entre o texto visual estático e o texto verbal escrito presente nessas imagens. De acordo com nossos dados, podemos avaliar que o ponto chave dessa relação se encontra na intertextualidade manifestada por meio das atrizes, atores e personagens famosos que são usados nas fotos divulgadas pela revista. Eles aparecem realizando ações que são comuns para a maioria das pessoas, como comer, dormir, sentir-se cansado ou motivado. Intrínseca a essas ações, está a estratégia usada pela Cosmopolitan para atrair o púbico, pois, ao tratar de assuntos que estão presentes no cotidiano da maioria das pessoas, a revista cria uma identidade para suas postagens, dissemina valores e acaba por se tornar uma espécie de porta-voz dos leitores.

Além disso, o fato de a Cosmopolitan utilizar o Instagram para disseminar esse tipo de conteúdo mostra que ela está seguindo a tendência de expansão dos meios de comunicação para o ambiente digital e se voltando para um público que é capaz de expandir a marca Cosmopolitan e o conteúdo por ela veiculado. Isso ocorre quando, por meio do uso de figuras conhecidas e da abordagem de temas vivenciados pela maioria das pessoas, a revista provoca a identificação dos leitores com a mensagem das imagens ao ponto desses leitores compartilharem as postagens em outros ambientes, como Facebook e Twitter, por exemplo, fazendo com que mais pessoas tenham contato com essas imagens e, consequentemente, elevando a abrangência do público-leitor da Cosmopolitan.

O referencial teórico-metodológico empregado neste estudo nos possibilitou uma análise sistemática das características do texto multimodal. Por meio das categorias de análise ofertadas pela Gramática do Design Visual de Kress e van Leeuwen (2006), pudemos investigar a natureza da representação visual, diferenciando imagens narrativas de imagens conceituais, o que nos levou a perceber como as postagens da Cosmopolitan no Instagram se apropriam de personagens e cenas amplamente difundidas para narrar histórias ou mobilizar e difundir conceitos subjacentes. Por um lado, narrar ou conceituar implica fazer escolhas e tomar decisões em prol da construção de sentidos específicos. Por outro lado, saber identificar tais estratégias é essencial para uma leitura eficiente e crítica o suficiente para desnaturalizar certas crenças ou valores. A teoria de Barthes nos ofereceu mecanismos de 
compreensão sobre a inter-relação entre verbal e visual, sobre como esses dois modos semióticos se reforçam ou complementam no processo de produção de sentido. Uma sugestão para pesquisas futuras seria o aprofundamento do estudo das relações intersemióticas em textos como os do corpus dessa pesquisa. O conceito de intertextualidade, especialmente conforme definido por Koch, Bentes e Cavalcante (2008), nos levou a olhar para "além do texto" de modo sistemático, observando os modos recorrentes como o intertexto é mobilizado para a produção de sentido em textos como os investigados.

Por fim, acreditamos que esta pesquisa contribui para promover uma reflexão sobre o papel dos veículos impressos inseridos em um novo ambiente, qual seja, o digital. Desconstruir e revelar a mecânica das postagens da Revista Cosmopolitan traz à tona as estratégias das quais se valem os meios impressos para levar a informação até seu público e como esses meios de comunicação estão se adaptando ao modo de manifestação dos sentidos cada vez mais multimodal, comportando, por conta disso, diversos formatos (texto, fotos, vídeos, áudios e a combinação de todos esses formatos). Nos dias atuais, estar engessado em um único formato de disseminação de sentido já não supre as necessidades da informação e é com essa nova realidade que os veículos de comunicação bem como os leitores estão tendo que lidar. 


\section{REFERÊNCIAS}

ANATEL. Agência Nacional de Telecomunicações. Dados de telefonia móvel no Brasil, 2016. Disponível em <http://www.anatel.gov.br/institucional/index.php/noticias/noticia-dados-01/1060-brasil-fecha-fevereiro-de-2016-com-258-06-mipho

ARAGÃO, R. M. Usos Jornalísticos do Instagram: aproximações a partir do JC Imagem. In: INTERCOM- XIV Congresso de Ciências da Comunicação na Região Nordeste, Recife, jun. 2012. Disponível em: <http://portalintercom.org.br/anais/nordeste2013/resumos/R370922-1.pdf>. Acesso em 9 abr. 2016.

BAKHTIN, M. Estética da criação verbal. São Paulo: Martins Fontes, 1997.

BARTHES, R. Elementos de Semiologia, São Paulo: Cultrix, 1964.

BARTHES, R. O óbvio e o obtuso: ensaios sobre fotografia, cinema, teatro e música. Rio de Janeiro: Nova Fronteira, 1990.

BRAGA, D. B. Ambientes digitais: reflexões teóricas e práticas. São Paulo: Cortez Editora, 2016.

CASTELLS, M. A Galáxia da Internet: reflexões sobre a internet, os negócios e a sociedade. Rio de Janeiro: Zahar, 2003.

COSTA, M. Como usar o Stories do Instagram. TechTudo, Brasil, 3 go. 2016. Disponível em: <http://www.techtudo.com.br/dicas-e-tutoriais/noticia/2016/08/como-usar-o-stories-do-instagram.html>. Acesso em: 28 mar. 2017.

FERREIRA, J. C. B; PADILHA, A. J. R. O Estadão no Instaram: do jornal impresso ao aplicativo móvel. Comunicação \& Mercado, Mato Grosso do Sul, v. 3, n. 8, p. 4-15, jul./dez. 2014. Disponível em: <http://www.unigran.br/mercado/paginas/arquivos/edicoes/8/9. pdf>. Acesso em: 9 abr. 2016.

FONTE, R.; CAIADO, R. Práticas Discursivas Multimodais no WhatsApp: uma análise verbo-visual. Desenredo: revista do programa de Pós-Graduação em Letras da Universidade de Passo Fundo, Passo Fundo, v. 10, n. 2, p. 475-487, jul./dez. 2014.

FREITAS, A. C. R. O Desenvolvimento do Conceito de Intertextualidade. Icarahy, n. 6, p. 27-42. 2011. Disponível em: <http://www.revistaicarahy.uff.br/revista/html/numeros/6/ dlingua/ANTONIO_CARLOS.pdf> Acesso em: 15 mai. 2016.

GONÇALVEZ, L. B. et.al. Diálogos entre Semiótica e Análise de Discurso: uma reflexão sobre o "emitir para existir" na linguagem do Instagram do @reveillindosmilagres. Cadernos de Graduação, Maceió, 2016. 
CADERNOS DE COMUNICAÇÃO

UNIVERSIDADE FEDERAL DE SANTA MARIA

HALLIDAY, M. A. K. Language as social semiotic: the social interpretation of language and meaning. Maryland. University Park Press, 1978.

HALLIDAY, M. A. K.; MATTHIESSEN, C. M. I. M. An introduction to functional

grammar. London: Edward Arnold, 2004.

HENDGES, G. R.; NASCIMENTO, R. G.; MARQUES, P. M. A Gramática da Imagem como ferramenta na análise crítica de gêneros midiáticos. In: SEIXAS, L.; PINHEIRO, N.F. et al. Gêneros: um diálogo entre Comunicação e Linguística. 1. ed. Florianópolis: Insular, 2013.

HISTÓRIA DO FACEBOOK. In: TECNOLOGIA Terra. Brasil: Terra Networks, 2014. Disponível em: <http://tecnologia.terra.com.br/facebook-completa-10-anos-conheca-a-historia-da-rede-social,c862b236f78f3410VgnVCM20000099cceboaRCRD.html>. Acesso em: 1 abr. 2016.

HODGE, R.; KRESS, G. Social Semiotics. Cambridge: Polity, 1988.

INSTAGRAM DA COSMOPOLITAN. Instagram. Brasil, 2016. Disponível em: <https://www. instagram.com/cosmopolitan.br/>. Acesso em: 1 abr. 2016.

KOCH, I. G. V. Argumentação e Linguagem. São Paulo: Cortez, 2008.

KOCH, I. G. V.; BENTES, A. C.; CAVALCANTE, M. M. Intertextualidade: diálogos possíveis. São Paulo: Cortez, 2008.

KRESS, G.; VAN LEEUWEN, T. Multimodal discourse: the modes and media of contemporary communication. Arnold: London, 2001.

KRESS, G.; VAN LEEUWEN, T. Reading images: the grammar of the design visual. London: Routledge, 2006.

KRISTEVA, J. Introdução à Semanálise. São Paulo: Perspectiva, 2005.

LARANGEIRA, A. N.; QUADROS, C. I. Assim caminha o jornalismo do século XXI: do digital ao neo-analógico. Compós, Curitiba, 2007. Disponível em: <http://www.gersonmartins. jor.br/dados/anexo/biblioteca_239[64].pdf>. Acesso em: 8 abr. 2016.

MANNARINO, M. V. R. O Papel do Web Jornal: veículo de comunicação e sistema de informação, Porto Alegre: EDIPUCRS, 2000.

MATOS, M. D. As múltiplas vozes no discurso dos moradores em situação de rua. In: CíRCULO DE ESTUDOS LINGUISTICOS DO SUL, Minas Gerais, CELSUL, 2008. Disponível em: <http://www. celsul.org.br/Encontros/08/multiplas_vozes_texto.pdf>. Acesso em 15 mai. 2016.

Rev.Cad.Comun. Santa Maria, v.22, n.1, art 8, p.194 de 197, jan/abr.2018 
MATTOS, S. A. S. A revolução digital e os desafios da comunicação. Cruz das Almas: UFRB, 2013.

MORAES, P. R. et.al. A teoria das representações sociais. Direito em Foco, São Paulo, p. 1-14, 2013. Disponível em: <http://unifia.edu.br/revista_eletronica/revistas/direito_foco/ artigos/ano2013/teoria_representacoes.pdf>. Acesso èm: 11 abr. 2016.

NASCIMENTO, R. G.; BEZERRA, F. A. S.; HEBERLE, V. M. Multiletramentos: iniciação à análise de imagens. Linguagem \& Ensinos, Pelotas, v. 14, n. 2, p. 529-552, jul./dez. 2011. Disponível em: <revistas.ucpel.tche.br/index.php/rle/article/view/38/24>. Acesso em: 11 abr. 2016.

OLIVEIRA, Y. R. O Instagram como uma nova ferramenta para estratégias publicitárias. In: INTERCOM- XVI Congresso de Ciências da Comunicação na Região Nordeste, João Pessoa, maio. 2014. Disponível em: <http://www.portalintercom.org.br/anais/nordeste2014/resumos/R42-0112-1.pdf>. Acesso em: 9 abr. 2016.

ORLANDI, E. P. Análise de Discurso: princípios e procedimentos. Campinas: Pontes, 2009.

PEREIRA, C. A. M.; HERSCHMANN, M. Comunicação e novas estratégias organizacionais na era da informação e do conhecimento. In: INTERCOM - XXV Congresso de Ciências da Comunicação, Salvador, set. 2002. Disponível em: <http://www.portcom.intercom.org. br/pdfs/98bode393280e73a1d33fa440160cdbf.pdf>. Acesso em: 9 abr. 2016.

PRINT SCREEN. Curto Muito, Brasil, 8 abr. 2014. Disponível em: <http://www.curtomuito. net.br/print-screen-como-fazer/>. Acesso em: 1 abr. 2016.

PUBLIABRIL. Site. Brasil, 2016. Disponível em: <http://publiabril.abril.com.br/marcas/cosmopolitan>. Acesso em: 23 mar. 2016.

SALAZAR, M. M. Consumir, Registrar, Compartilhar: a hashtag \#lookdodia na sociedade de consumo. In: VIII Simpósio Nacional da ABCiber - comunicação e cultura na era de tecnologias midiáticas onipresentes e oniscientes, São Paulo, dez. 2014. Disponível em: <http://www.abciber.org.br/simposio2014/anais/GTs/manuela_de_mattos_salazar_174. pdf>. Acesso em: 9 abr. 2016.

SANTAELLA, L.; NÖTH, W. Imagem: cognição, semiótica, mídia. 4. ed. São Paulo: Iluminuras, 2005.

SANTOS, E. P. A intertextualidade na construção argumentativa do artigo de opinião. Diálogo das Letras, Pau dos Ferros, v. 2, n. 1, p. 300 - 314, jan./jun. 2013. Disponível em: <http://periodicos.uern.br/index.php/dialogodasletras/article/viewFile/545/286>. Acesso em: 15 mai. 2016. 
CADERNOS DE COMUNICAÇÃO

UNIVERSIDADE FEDERAL DE SANTA MARIA

SANTOS, M. J. S.; GOMES, S. A.; PELLEGRINI, P. A. E. S. As Redes Sociais como Ferramentas para o Jornalismo: as práticas de O Imparcial Online. In: INTERCOM-XXVIII Congresso de Ciências da Comunicação, Rio de Janeiro, set. 2015. Disponível em: <http://docplayer. com.br/15430272-As-redes-sociais-como-ferramentas-para-o-jornalismo-as-praticas-de-o-imparcial-online-1.html>. Acesso em: 23 mar. 2016.

SANTOS, Z. B.; MEIA, A. C. G. A. A produção de textos multimodais: a articulação dos modos semióticos. RevLet, Minas Gerais, v. 2, n. 1, p. 304-318, 2010. Disponível em: <http://www.revlet.com.br/artigos/15.pdf>. Acesso em: 9 abr. 2016.

SILVA, R. C. História do jornalismo: evolução e transformação. Revista Temática, São Paulo, v. 8, n. 7, jul. 2012. Disponível em: <http://www.insite.pro.br/2012/julho/historia jornalismo_evolucao.pdf>. Acesso em: 19 mar. 2016.

SMAAL, Beatriz. A história do Twitter. TecMundo, Brasil, 19 fev. 2010. Disponível em: <http://www.tecmundo.com.br/rede-social/3667-a-historia-do-twitter.htm>. Acesso em: 1 abr. 2016.

SPERANDIO, N. E. A influência multimodal dos textos digitais na construção de sentido a partir da interação metafórica e metonímica. In: Anais do SEMINÁRIO NACIONAL DE EDUCAÇÃO PROFISSIONAL E TECNOLOGIA, 2012, Minas Gerais, SENEPT, 2012. Disponível em: <http://www.senept.cefetmg.br/galerias/Anais_2012/GT-10/GT10-004.pdf>. Acesso em: 9 abr. 2016.

TEIXEIRA, L.; FARIA, K.; SOUZA, S. Textos multimodais na aula de português: metodologia de leitura. Desenredo, Passo Fundo, v. 10, n. 2, p. 314-336, jul./dez. 2014. Disponível em: <http://www.upf.br/seer/index.php/rd/article/viewFile/4295/3095>. Acesso em: 12 mar. 2016.

USUÁRIOS BRASILEIROS NO FACEBOOK. G1, São Paulo, 5 jan. 2012. Disponível em: <http://g1.globo.com/tecnologia/noticia/2012/01/numero-de-usuarios-brasileiros-no-facebook-cresce-298-em-2011.html>. Acesso em: 1 abr. 2016.

VAN LEEUWEN, T. Introducing social semiotics. New York: Routledge, 2001.

VIEIRA, T. M. A Fotografia e as novas mídias: como o instagram alterou a forma de produzir imagens. In: INTERCOM - XXVIII Congresso de Ciências da Comunicação, Rio de Janeiro, set. 2015. Disponível em: <http://docplayer.com.br/3468032-A-fotografia-e-as-novas-midias-como-o-instagram-alterou-a-forma-de-produzir-imagens-1.html>. Acesso em: 2 abr. 2016.

VIRGINO, R.; BEZERRA, E. P.; NICOLAU, M. As transformações e as novas práticas da profissão. Temática, Paraíba, v. 7, n. 9, p. 1-13, set. 2011. Disponível em: <http://www.insite. pro.br/2011/setembro/jornalismo_midiassociais_profissao.pdf>. Acesso em: 2 abr. 2016.

WHATSAPP MESSENGER. WhatsApp. Brasil, 2016. Disponível em: <https://www.whatsapp.com/?l=pt_br>. Acesso em: 2 abr. 2016.

Rev.Cad.Comun. Santa Maria, v.22, n.1, art 8, p.196 de 197, jan/abr.2018 
ZUCKERBERG, Mark. Resultado Trimestral. Estados Unidos, 2017. Disponível em: < https://www.facebook.com/photo.php?fbid=10103472646530311\&se$\mathrm{t}=\mathrm{pb} .4 .-2207520000.1489793920 . \&$ type $=3 \&$ theater $>$.

\section{Vanessa Harlos}

Jornalista formada pela Universidade Federal de Santa Maria - campus Frederico Westphalen (2017). Atualmente atua no Jornal Folha do Noroeste de Frederico Westphalen.

E-mail:vane.harllos@gmail.com

\section{Cristiane Salete Florek}

Mestra em Letras pela Universidade Federal de Santa Maria (2015), atualmente, é bolsista de doutorado da mesma universidade. Tem experiência na área de Linguística, com ênfase em Linguística Aplicada, em temas como: Análise Crítica de Gênero, Análise do Discurso Multimodal, Multiletramentos.

E-mail:crisflorek@hotmail.com

RECEBIDO EM: 30/03/2017

ACEITO EM: 30/05/2017 